\title{
Enraizamento de estacas semilenhosas de Pereskia aculeata nas quatro estações do ano em diferentes substratos
}

Luciele Milani Zem ${ }^{1 *}$, Katia Christina Zuffellato-Ribas ${ }^{2}$ e Henrique Soares Koehler ${ }^{3}$

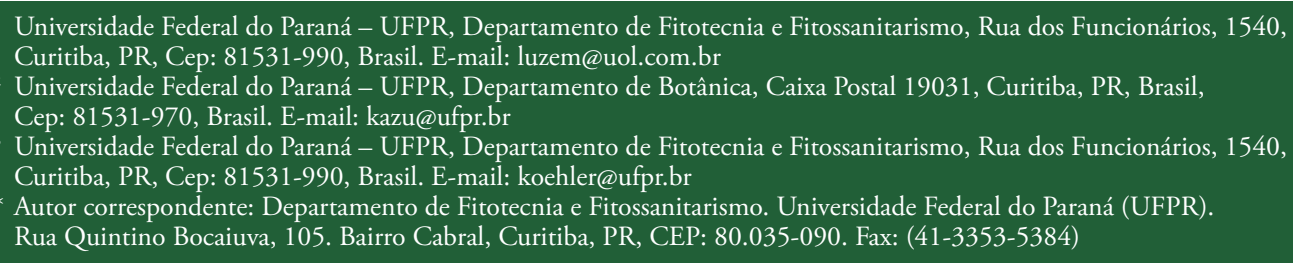

ISSN 2448-0479

Resumo - Pereskia aculeata Mill. é uma espécie pertencente à família Cactaceae, popularmente conhecida como ora-pro-nobis. Possui valor na medicina popular brasileira, sendo utilizada como emoliente, além de possuir minerais, vitaminas e elevado teor proteico. Por ser uma espécie com semente recalcitrante, o que pode ser considerado uma dificuldade para a multiplicação via sementes. Assim, objetivou-se estudar a propagação vegetativa por meio da indução do enraizamento de estacas semilenhosas, coletadas de plantas matrizes adultas, submetidas a diferentes tipos de substratos, coletadas nas quatro estaçóes do ano (outono/2014, inverno/2014, primavera/2014 e verão/2015). As estacas foram confeccionadas com 10-12 cm de comprimento, corte em bisel na base e reto no ápice, mantendo-as com duas folhas com sua área reduzida à metade. Após a desinfestação, foram acondicionadas em tubetes de polipropileno contendo os seguintes substratos: vermiculita, Plantmax ${ }^{\oplus}$ e as misturas vermiculita:casca de arroz carbonizada (1:1), vermiculita:Plantmax ${ }^{\oplus}$ (1:1). O delineamento utilizado foi o inteiramente casualizado, em arranjo fatorial de 4 estaçóes do ano $\mathrm{x} 4$ tipos de substratos, com quatro repetiçóes contendo 20 estacas por unidade experimental. Após 50 dias em casa de vegetação, foi avaliada a porcentagem de estacas enraizadas, massa fresca e seca das raízes, porcentagem de estacas com calos, vivas, mortas, com novas brotaçóes e que mantiveram suas folhas iniciais. Concluiu-se que Pereskia aculeata pode ser considerada uma espécie de fácil enraizamento, com porcentagens de indução radicial superiores a $88 \%$ em todas as estaçóes estudadas, sendo recomendado o uso do substrato Plantmax ${ }^{\oplus}$.

Palavras-chave - Carne de pobre. Hortaliça não-convencional. Estaquia. Rizogênese.

Abstract - Pereskia aculeata Mill. is a specie of the Cactaceae family, popularly known as ora-pro-nobis. It has value in Brazilian folk medicine and is used as an emollient and also has minerals, vitamins and high protein content. Being a recalcitrant species, it is considered difficult multiplication via seeds. The objective was to study the vegetative propagation through the induction of rooting softwood cuttings collected from plants grown arrays, submitted to different types of substrates, collected in four seasons (fall/2014, winter/2014, spring/2014 and summer/2015). The cuttings were made with $10-12 \mathrm{~cm}$ long, cut bevel on the bottom and straight at the apex, keeping them with two leaves with their area reduced by half. After disinfection, they were placed in polypropylene tubes containing the following substrates: vermiculite, vermiculite Plantmax ${ }^{\oplus}$ and mixtures:carbonized rice hulls (1:1), vermiculite:Plantmax ${ }^{\odot}$ $(1: 1)$. The design was completely randomized in a factorial arrangement of 4 seasons $x 4$ types of substrates, with four replicates and 20 cuttings each. After 50 days in the greenhouse, it evaluated the percentage of rooted cuttings, fresh and dry weight of roots, percentage of cuttings with callus, living, dead, with new 
shoots and kept their leaves early. It was concluded that Pereskia aculeata can be considered a kind of easy rooting with radicial induction percentages exceeding $88 \%$ in all studied stations, and recommended the use of Plantmax substrate.

Keywords - Poor meat. Unconventional vegetable. Cutting. Rhizogenesis.

Recebido em: 15 de setembro de 2016.

Aprovado em: 22 de novembro de 2016.

\section{INTRODUÇÃO}

Pereskia aculeata Mill. é uma espécie pertencente à família Cactaceae e à subfamília Pereskioideae. Popularmente é conhecida como ora-pro-nobis, do latim "rogai por nós", e como carne-de-pobre, devido ao alto teor de proteína encontrado em suas folhas (MANKE, 1998; SOUZA; LORENZI, 2005).

A espécie apresenta potencial para usos na atenuação de processos inflamatórios e na recuperação da pele em casos de queimadura devido ao alto teor de mucilagem presente em suas folhas, sendo empregada como emoliente na medicina popular (DUARTE; HAYASHI, 2005). Além disso, Pereskia aculeata possui minerais (cálcio, magnésio, manganês e zinco), vitaminas (A, C e ácido fólico) e proteínas essenciais, tornando-se de grande utilidade no combate à desnutrição em seres humanos (TAKEITI et al., 2009).

Pereskia aculeata é considerada uma trepadeira arbustiva semilenhosa, de caule não suculento e ereto quando jovem (MANKE, 1998). Seus frutos quando maduros possuem de duas a três sementes, as quais são pretas, brilhantes e de formato lenticular (ROSA; SOUZA, 2003). Suas sementes apresentam comportamento recalcitrante, germinando logo após a dispersáo ou enquanto ainda na planta matriz, devido ao elevado teor de água nestas (VOZZO, 2002).

A multiplicação por meio da propagação vegetativa via estaquia caulinar é uma das técnicas mais utilizadas, pois possibilita a uniformidade e qualidade das mudas (HARTMANN et al., 2011).

Fatores intrínsecos à planta estão relacionados à facilidade de enraizamento, como condiçôes fisiológicas e idade da planta matriz ou das estacas, potencial genético, sanidade do material vegetal e balanço hormonal (FACHINELLO; HOFFMANN; NACHTIGAL, 1995). Outros fatores ainda podem exercer influência como a temperatura, luz, umidade, substrato, lesão na base da estaca, tipo de estaca, época de coleta e aplicação de reguladores vegetais (OLIVEIRA et al., 2009).

A qualidade do substrato é outro fator importante para o sucesso do enraizamento de estacas em diversas espécies. Além das substâncias de reserva utilizadas pela planta, o substrato ideal é aquele que serve de suporte para a sustentação da estaca, retém água fornecida e fornece ambiente escuro e aeração para a base da estaca a fim de proporcionar uma melhor porcentagem de enraizamento bem como sobre a qualidade das raízes formadas (PIO et al., 2005)

Os substratos vermiculita, Plantmax e casca de arroz carbonizada possuem alta capacidade de retenção de água (CARDOSO et al., 2011), porém a vermiculita retém de 4 a 5 vezes seu peso em água devido possuir baixa densidade e sua granulometria variar de $1 \mathrm{a} 2 \mathrm{~mm}$ de diâmetro, promovendo assim a formação de poros de tamanho intermediário, os quais são responsáveis pela retenção de água (GONÇALVES, 1995; FERRAZ; CETURION; BEUTLER, 2005).

Da mesma forma, a estação do ano pode exercer influência determinante sobre o enraizamento (SARZI; PIVETTA, 2008), portanto para cada espécie é preciso determinar a melhor época para a coleta do material, visto que ela está diretamente relacionada com a condição fisiológica da planta matriz (HARTMANN et al., 2011).

Estudos agronômicos sobre a espécie são ainda escassos e apesar de suas características nutricionais, existem poucas informaçôes sobre seu cultivo, principalmente em relação a métodos de propagação. Assim, objetivou-se estudar o enraizamento de estacas semilenhosas de Pereskia aculeata coletadas nas quatro estaçóes do ano, submetidas a diferentes tipos de substrato, visando estabelecer um protocolo de propagação desta espécie, que além de nativa, é tão importante em termos nutricionais.

\section{MATERIAIS E MÉTODOS/METODOLOGIA}

O material vegetativo de Pereskia aculeata Mill. foi coletado em Curitiba (PR), sob as coordenadas $25^{\circ} 26^{\prime} 13.21^{\prime \prime}$ de latitude Sul e $49^{\circ} 20^{\prime} 22.40^{\prime \prime}$ de longitude Oeste, $934 \mathrm{~m}$ de altitude. Segundo classificação de Köppen, o clima da regiâo é do tipo Cfb, isto é, clima caracterizado como temperado úmido com temperatura média do mês mais quente acima de $10^{\circ} \mathrm{C}$, com veróes suaves e inverno com geadas frequentes e tendência de concentração de chuva nos meses de verão, contudo sem estação seca definida. Amostras secas da espécie foram depositadas no her- 
bário da Universidade Federal do Paraná (UFPR) com a classificação no UPCB 75848.

O experimento foi conduzido na casa de vegetação do Setor de Ciências Biológicas, da Universidade Federal do Paraná, em Curitiba - PR. O material vegetativo utilizado consistiu de ramos oriundos de 4 plantas matrizes, entre cinco a dez anos de idade, as quais estavam a campo e não receberam nenhum trato cultural como adubação, irrigação entre outros. $\mathrm{O}$ material foi coletado nos meses de abril/2014 (outono), julho/2014 (inverno), outubro/2014 (primavera) e janeiro/2015 (verão).

A partir destes ramos foram confeccionadas estacas caulinares semilenhosas com aproximadamente $10-12 \mathrm{~cm}$ de comprimento, com corte reto no ápice e em bisel na base, sendo mantidas duas folhas na porção apical com sua área reduzida à metade. Após a confecção, estas foram submetidas à desinfestação em hipoclorito de sódio a $0,5 \%$ durante 10 minutos, sendo posteriormente lavadas em água corrente por 5 minutos.

As estacas foram então plantadas em tubetes de polipropileno com capacidade de $53 \mathrm{~cm}^{3}$, contendo os substratos, conforme os respectivos tratamentos: vermiculita granulometria fina, Plantmax ${ }^{\circ}$ (vermiculita explandida, casca de pinus e perlita) e as misturas vermiculita granulometria fina:casca de arroz carbonizada (1:1) e vermiculita de granulometria fina:Plantmax ${ }^{\circ}(1: 1)$. O experimento, em todas as estaçóes do ano, foi conduzido em casa de vegetação climatizada com nebulização intermitente, com umidade relativa do ar de $80 \%$ e temperatura entre 20 e $30^{\circ} \mathrm{C}$.

O experimento foi conduzido em delineamento experimental inteiramente casualizado, com um arranjo fatorial $4 \times 4$ ( 4 estaçóes do ano $\mathrm{x} 4$ tipos de substratos), com quatro repetições contendo 20 estacas por unidade experimental, totalizando 320 estacas por estação do ano.

Após 50 dias da instalação dos experimentos, em cada estaçấo do ano, foram avaliadas as seguintes variáveis: porcentagem de estacas enraizadas (estacas vivas que apresentaram raízes de, no mínimo $1 \mathrm{~mm}$ de comprimento, podendo ou não apresentar calos); massa fresca de raízes; massa seca de raízes (raízes secas em estufa de ventilação forçada a $60^{\circ} \mathrm{C}$, até massa constante); estacas com calos (estacas vivas, sem raízes, com formação de massa celular indiferenciada na base); estacas vivas (estacas vivas, sem a formação de raízes ou calos); estacas mortas (estacas que apre- sentavam tecidos necrosados); estacas com brotação (estacas que formaram novas brotaçóes no ápice) e estacas que mantiveram as folhas originais.

As variâncias dos tratamentos foram testadas quanto à homogeneidade pelo teste de Bartlett. As variáveis, cujas variâncias dos tratamentos se mostraram homogêneas, e foram submetidas à análise de variância e, quando apresentaram diferenças significativas pelo teste $\mathrm{F}$, tiveram suas médias comparadas pelo teste de Tukey ao nível de 5\% de probabilidade, e seus dados expressos em porcentagem.

\section{RESULTADOS E DISCUSSÁO}

A interação entre os tipos de substratos (vermiculita, vermiculita:casca de arroz carbonizada, vermiculita:Plantmax ${ }^{\oplus}$ e Plantmax ${ }^{\circledR}$ e estaçóes do ano (outono, inverno, primavera e verão) foi significativa, pelo Teste de comparação de mTukey a $5 \%$ de probabilidade, para as variáveis porcentagem de enraizamento de Pereskia aculeata, massa fresca e seca de raízes, porcentagem de estacas com calos, vivas, mortas, com brotação e que mantiveram as folhas originais na estaca, demonstrando que estes fatores são dependentes (Tabela 1).

Tabela 1 - Resultados da análise de variância de estacas de Pereskia aculeata Mill. para as variáveis: estacas enraizadas (EE), massa fresca de raízes (MF), massa seca de raízes (MS), estacas com calos (EC), vivas (EV), mortas (EM), com brotaçáo (EB) e que mantiveram folhas (EMF) em quatro estações do ano, submetidas a diferentes tipos de substratos, Curitiba (PR), 2015.

\begin{tabular}{|c|c|c|c|c|}
\hline Trat & $\mathrm{EE}$ & $\mathrm{MF}$ & MS & $\mathrm{EC}$ \\
\hline Estação & $6331,77^{* *}$ & $217,30^{* *}$ & $7,32^{* *}$ & $451,56^{* *}$ \\
\hline Substrato & $254,68^{*}$ & $26,11^{* *}$ & $0,36^{* *}$ & $39,06^{*}$ \\
\hline ExS & $426,56^{* *}$ & $15,79^{* *}$ & $0,32^{* *}$ & $39,06^{* *}$ \\
\hline Trat & $1753,22^{* *}$ & $58,15^{* *}$ & $1,73^{* *}$ & $121,56^{* *}$ \\
\hline Erro & 70,57 & 2,07 & 0,00 & 13,89 \\
\hline \multicolumn{5}{|l|}{ Total } \\
\hline $\mathrm{CV}$ & 10,44 & 17,05 & 3,13 & 140,34 \\
\hline$X^{2}$ & 21,78 & 22,82 & 23,35 & 20,64 \\
\hline Trat & $\mathrm{EV}$ & EM & EB & EMF \\
\hline Estação & $663,93^{* *}$ & $8683,68^{* *}$ & $4126,43^{* *}$ & $14635,41^{* *}$ \\
\hline Substrato & $76,43^{* *}$ & $664,51^{* *}$ & $216,01^{\mathrm{ns}}$ & $1080,20^{* *}$ \\
\hline ExS & $34,76^{*}$ & $611,25^{* *}$ & $1035,11^{* *}$ & $2282,98^{* *}$ \\
\hline Trat & $168,93^{* *}$ & $2236,39^{* *}$ & $1489,55^{* *}$ & $4512,91^{* *}$ \\
\hline Erro & 12,82 & 14,76 & 155,33 & 108,66 \\
\hline \multicolumn{5}{|l|}{ Total } \\
\hline $\mathrm{CV}$ & 86,50 & 29,74 & 17,21 & 20,98 \\
\hline $\mathrm{X} 2$ & 24,95 & 20,32 & 18,48 & 24,61 \\
\hline
\end{tabular}

ExS= Estaçẫo x Susbtrato; $C V=$ coeficiente de variação; $\mathrm{X}^{2}=$ Teste de Bartlett 
De acordo com os resultados, os substratos vermiculita, vermiculita:casca de arroz carbonizada e Plantmax ${ }^{\bullet}$ apresentaram elevados percentuais de enraizamento (81 - 98\%) em todas as estaçóes do ano, não diferindo estatisticamente entre si (Tabela 2).

Tabela 2 - Porcentagem de enraizamento de estacas de Pereskia aculeata Mill., coletadas nas quatro estações do ano e submetidas a tratamentos com diferentes tipos de substrato, Curitiba (PR), 2015.

\begin{tabular}{ccccc}
\hline Trat & Out & Inv & Prim & Veráo \\
\hline V & $86,25 \mathrm{abA}$ & $81,25 \mathrm{aA}$ & $93,75 \mathrm{aA}$ & $82,50 \mathrm{aA}$ \\
V:C & $81,25 \mathrm{bA}$ & $88,75 \mathrm{aA}$ & $96,25 \mathrm{aA}$ & $90,00 \mathrm{aA}$ \\
V:P & $78,75 \mathrm{bA}$ & $60,00 \mathrm{bB}$ & $27,50 \mathrm{bC}$ & $38,75 \mathrm{bC}$ \\
P & $98,75 \mathrm{aA}$ & $88,75 \mathrm{aA}$ & $97,50 \mathrm{aA}$ & $97,50 \mathrm{aA}$ \\
\hline CV $(\%)$ & \multicolumn{5}{c}{10,44} \\
\hline
\end{tabular}

$\mathrm{V}=$ vermiculita; $\mathrm{V}: \mathrm{C}=$ vermiculita:casca de arroz carbonizada; $\mathrm{V}: \mathrm{P}=$ vermiculita:Plantmax $; \mathrm{P}=$ Plantmax $; \mathrm{CV}=$ coeficiente de variação. Médias seguidas de mesma letra na coluna (minúscula) e na linha (maiúscula) não diferem estatisticamente pelo teste de Tukey ao nível de $5 \%$ de significância

Higa, Fior e Rodrigues (2012), estudando o uso de diferentes tipos de substratos na propagação vegetativa de Pereskia aculeata constataram que, independente do substrato utilizado, o enraizamento das estacas foi considerado satisfatório (91\%). No presente trabalho, apenas o uso da mistura vermiculita:Plantmax ${ }^{\bullet}$ apresentou os menores percentuais de enraizamento, marcadamente nas estaçóes de primavera $(27,50 \%)$ e verão $(38,75 \%)$, sendo considerado insatisfatório, uma vez que houve uma baixa porcentagem de estacas enraizadas (Tabela 2).

A utilização de diferentes substratos é uma das formas empregadas a fim de se verificar a eficiência da propagação de diversas espécies (CAVALCANTI; REZENDE, 2007). De acordo com os resultados obtidos, observa-se que a mistura vermiculita:Plantmax ${ }^{\odot}$ não contribuiu para a boa formação das mudas de Pereskia aculeata. Tais resultados podem estar relacionados ao fato do substrato ser uma parte importante no processo do enraizamento, podendo influenciar na formação da planta (SOUZA et al., 2006).

A baixa porcentagem de enraizamento, quando no uso da mistura vermiculita:Plantmax ${ }^{\circ}$, observada nas estaçóes inverno $(60,00 \%)$, primavera $(27,50 \%)$ e verão $(38,75 \%)$ quando comparada com o outono $(78,75 \%)$, pode ainda estar relacionada à condição fisiológica da planta matriz no momento da coleta.

As menores porcentagens de enraizamento para a mistura vermiculita:Plantmax ${ }^{\ominus}$ em todas as estaçôes do ano podem ter ocorrido em função das suas propriedades físico-químicas, como a boa aeração, alta absorção e retenção de água (SKREBSKY; NICOLOSO; MALDANER, 2006).

Houve um decréscimo na porcentagem de enraizamento com a utilização de substratos com a presença de vermiculita e, com isso, pode-se dizer que Pereskia aculeata se adapta melhor a substratos com menos água.

As características físicas dos substratos mostram que o substrato Plantmax ${ }^{\curvearrowleft}$ apresenta maior porosidade e, portanto maior aeração quando comparado com a vermiculita, com $46,50 \%$ e $32,70 \%$, respectivamente (PIO et al., 2005). Devido a esse fato, o substrato Plantmax ${ }^{\oplus}$ propicia melhor produção de massa seca e enraizamento de estacas (SOUSA; AYALA-OSUNA; GOMES, 2005), pois substratos com maior porosidade facilitam o crescimento radicial; assim, além de ter maior massa, as raízes terão maior superfície de contato devido a maior área de exploração, possibilitando melhor absorção de nutrientes (TAVARES et al., 2012).

Nas estaçôes de inverno, primavera e verão, os substratos Plantmax ${ }^{\oplus}$, vermiculita e vermiculita: casca de arroz carbonizada apresentaram alto enraizamento; então, pode-se dizer que a espécie, apesar de ser adaptada a ambientes com restrição hídrica, necessita de substratos suficientemente úmidos para enraizar. Para a produção de mudas comerciais, a superioridade numérica de enraizamento, em todas as estaçóes do ano, observada com o uso de Plantmax ${ }^{\oplus}$, somada ao fato de se usar um único substrato comercial sem a necessidade de procedimento de mistura, pode ser determinante na escolha deste substrato.

Para a variável massa fresca de raízes/estaca, o uso de vermiculita:Plantmax ${ }^{\bullet}$ não apresentou diferença significativa entre as estaçóes do ano estudadas. O substrato vermiculita apresentou maior massa fresca nas estaçóes da primavera $(11,25 \mathrm{~g}) \mathrm{e}$ verão $(10,75 \mathrm{~g})$, não havendo diferença estatística entre si. Já a vermiculita:casca de arroz carbonizada apresentou na primavera, a maior massa fresca de raízes/estaca $(7,46 \mathrm{~g})$, diferindo estatisticamente apenas da estação do outono $(3,58 \mathrm{~g})$. Com o uso de Plantmax ${ }^{\oplus}$, as estações do inverno e primavera apresentaram os melhores resultados de massa fresca de raízes/estaca, 14,53 g e 17,08 g, respectivamente, diferindo estatisticamente das estaçóes de outono $(11,09 \mathrm{~g})$ e verão $(11,59 \mathrm{~g})$ (Tabela 3). Analisando as estaçóes do ano, o substrato Plantmax ${ }^{\bullet}$ foi aquele a apresentar maior massa fresca de raízes/estaca 
no outono $(11,09 \mathrm{~g})$, inverno $(14,53 \mathrm{~g})$ e primavera $(17,08 \mathrm{~g})$, diferindo estatisticamente dos demais substratos. No entanto, na estação do verão, o uso de Plantmax ${ }^{\oplus}(11,59 \mathrm{~g})$ não diferiu estatisticamente apenas do substrato vermiculita $(10,75 \mathrm{~g})$.

Tabela 3 - Massa fresca de raízes (g) de estacas de Pereskia aculeata Mill., coletadas nas quatro estaçóes do ano e submetidas a tratamentos com diferentes tipos de substrato, Curitiba (PR), 2015.

\begin{tabular}{ccccc}
\hline Trat & Out & Inv & Prim & Verão \\
\hline V & $7,00 \mathrm{bB}$ & $5,75 \mathrm{bB}$ & $11,25 \mathrm{bA}$ & $10,75 \mathrm{aA}$ \\
$\mathrm{V}: \mathrm{C}$ & $3,58 \mathrm{cB}$ & $5,88 \mathrm{bAB}$ & $7,46 \mathrm{cA}$ & $5,90 \mathrm{bAB}$ \\
V:P & $6,70 \mathrm{bA}$ & $6,02 \mathrm{bA}$ & $4,84 \mathrm{cA}$ & $5,68 \mathrm{bA}$ \\
$\mathrm{P}$ & $11,09 \mathrm{aB}$ & $14,53 \mathrm{aA}$ & $17,08 \mathrm{aA}$ & $11,59 \mathrm{aB}$ \\
\hline $\mathrm{CV}(\%)$ & \multicolumn{4}{c}{17,05} \\
\hline
\end{tabular}

$\mathrm{V}=$ vermiculita; $\mathrm{V}: \mathrm{C}=$ vermiculita:casca de arroz carbonizada; $\mathrm{V}: \mathrm{P}=$ vermiculita:Plantmax $; \mathrm{P}=$ Plantmax ${ }^{\oplus}$ CV= coeficiente de variação. Médias seguidas de mesma letra na coluna (minúscula) e na linha (maiúscula) não diferem estatisticamente ao nível de $5 \%$ de significância

A variável massa seca de raízes não mostrou diferença significativa para todas as estações do ano nos substratos vermiculita:casca de arroz carbonizada e vermiculita:Plantmax ${ }^{\bullet}$. No entanto, o uso da vermiculita não apresentou diferença estatística para as estaçōes da primavera $(2,6 \mathrm{~g})$ e verão $(2,53 \mathrm{~g})$, sendo que nestas estações houve maior produção de massa seca de raízes/estaca. Com o uso de Plantmax ${ }^{\circ}$ a maior produção de massa seca de raízes/estaca se deu na estação da primavera $(4,66 \mathrm{~g})$, a qual diferiu das demais estações (Tabela 4).

Tabela 4 - Massa seca de raízes (g) de estacas de Pereskia aculeata Mill., coletadas nas quatro estaçóes do ano e submetidas a tratamentos com diferentes tipos de substrato, Curitiba (PR), 2015.

\begin{tabular}{ccccc}
\hline Trat & Out & Inv & Prim & Verão \\
\hline V & $2,26 \mathrm{cB}$ & $2,20 \mathrm{cB}$ & $2,60 \mathrm{cA}$ & $2,53 \mathrm{cA}$ \\
V:C & $2,97 \mathrm{bA}$ & $2,95 \mathrm{bA}$ & $2,95 \mathrm{bA}$ & $2,93 \mathrm{bA}$ \\
V:P & $2,99 \mathrm{bA}$ & $2,95 \mathrm{bA}$ & $2,89 \mathrm{bA}$ & $2,91 \mathrm{bA}$ \\
P & $3,42 \mathrm{aD}$ & $4,21 \mathrm{aB}$ & $4,66 \mathrm{aA}$ & $3,76 \mathrm{aC}$ \\
\hline CV $(\%)$ & \multicolumn{5}{c}{3,13} \\
\hline
\end{tabular}

$\mathrm{V}=$ vermiculita; $\mathrm{V}: \mathrm{C}=$ vermiculita:casca de arroz carbonizada; $\mathrm{V}: \mathrm{P}=$ vermiculita:Plantmax ${ }^{\oplus} ; \mathrm{P}=\mathrm{Plantmax}^{\oplus} ; \mathrm{CV}=$ coeficiente de variação. Médias seguidas de mesma letra na coluna (minúscula) e na linha (maiúscula) nâo diferem estatisticamente pelo teste de Tukey ao nível de $5 \%$ de significância

Em todas as estações do ano estudadas o uso do substrato Plantmax ${ }^{\bullet}$ apresentou maior massa seca de raízes/estaca, diferindo estatisticamente dos demais substratos, enquanto que o substrato vermiculita, em todas as estaçôes do ano, foi o que apresentou os menores valores (Tabela 4).
A maior massa fresca e seca de raízes/estaca também pode influenciar na escolha do substrato, uma vez que determina uma maior massa de raízes, facilitando na maior absorção de água e nutrientes, fator essencial para o bom desenvolvimento das mudas (LIMA et al., 2009). Portanto, mudas com sistema radicial bem desenvolvido são melhor ancoradas no campo, possibilitando um desenvolvimento rápido $\mathrm{e}$ vigoroso, além de aumentar as chances de sobrevivência das mesmas (REIS et al., 2000).

Para a variável estacas com calos, apenas a vermiculita:casca de arroz carbonizada apresentou diferença significativa comparando-se as estaçôes do ano, sendo que o outono foi a estação que apresentou maior porcentagem de estacas com calos (18,75\%). No outono, inverno e verão, o uso da vermiculita:casca de arroz carbonizada apresentou maior porcentagem de estacas com calos, $18,75 \%, 11,25 \%$ e $8,75 \%$, respectivamente. Os demais substratos não apresentaram formação de estacas com calos.

A formação de calos e de raízes adventícias são fenômenos independentes, os quis podem ou não ocorrer simultaneamente, ambos envolvendo processo de divisão celular (HARTMANN et al., 2011). Para Pereskia aculeata, observou-se que não é necessário o surgimento do calo para posterior desenvolvimento das raízes adventícias, demonstrando, pelos resultados obtidos, que a espécie apresenta rizogênese direta e podendo ser considerada de fácil enraizamento.

Com relação à porcentagem de estacas vivas, apenas o substrato vermiculita apresentou diferença significativa ao ser comparado nas quatro estaçôes do ano. A primavera foi a estação que apresentou menor porcentagem de estacas vivas $(5,00 \%)$, e as estaçốes do outono $(13,75 \%)$, inverno $(18,75 \%)$ e verão $(17,50 \%)$ não diferiram significativamente entre si.

Quanto à mortalidade das estacas, o uso do substrato vermiculita e vermiculita:casca de arroz carbonizada não apresentou diferença significativa entre as estaçóes do ano. No entanto, o uso da vermiculita:Plantmax ${ }^{\circledR}$ apresentou, na primavera, um alto índice de mortalidade $(72,50 \%)$, diferindo significativamente das demais estaçôes, sendo que a estaçấo de outono foi a que apresentou menor porcentagem de estacas mortas $(18,75 \%)$. O substrato Plantmax ${ }^{\odot}$ apresentou maior porcentagem de estacas mortas na estação do inverno $(7,50 \%)$, diferindo apenas da estação do outono, com menor mortalidade $(0,00 \%)$ (Tabela 5$)$. 
Tabela 5 - Porcentagem de estacas mortas em Pereskia aculeata Mill., coletadas nas quatro estaçóes do ano e submetidas a tratamentos com diferentes tipos de substrato, Curitiba (PR), 2015.

\begin{tabular}{ccccc}
\hline Trat & Out & Inv & Prim & Verão \\
\hline V & $0,00 \mathrm{bA}$ & $0,50 \mathrm{bcA}$ & $1,25 \mathrm{bA}$ & $0,00 \mathrm{bA}$ \\
V:C & $0,00 \mathrm{bA}$ & $0,00 \mathrm{cA}$ & $0,00 \mathrm{bA}$ & $1,25 \mathrm{bA}$ \\
V:P & $18,75 \mathrm{aD}$ & $36,25 \mathrm{aC}$ & $72,50 \mathrm{aA}$ & $63,75 \mathrm{aB}$ \\
$\mathrm{P}$ & $0,00 \mathrm{bB}$ & $7,50 \mathrm{bA}$ & $2,50 \mathrm{bAB}$ & $2,50 \mathrm{bAB}$ \\
\hline CV $(\%)$ & \multicolumn{4}{c}{29,74} \\
\hline
\end{tabular}

$\mathrm{V}=$ vermiculita; $\mathrm{V}: \mathrm{C}=$ vermiculita:casca de arroz carbonizada; $\mathrm{V}: \mathrm{P}=$ vermiculita:Plantmax $; \mathrm{P}=$ Plantmax ${ }^{\oplus}$; $\mathrm{CV}=$ coeficiente de variação. Médias seguidas de mesma letra na coluna (minúscula) e na linha (maiúscula) não diferem estatisticamente pelo teste de Tukey ao nível de 5\% de significância

O substrato vermiculita:Plantmax ${ }^{\oplus}$, em todas as estaçôes do ano, apresentou maior porcentagem de estacas mortas comparado com os demais substratos. Como essa variável é complementar ao enraizamento e sobrevivência, estacas que não enraizaram acabaram morrendo.

Taxas de mortalidade em torno de $10-20 \%$ são consideradas toleráveis em processos de propagação vegetativa, visto que existe variabilidade genética entre as matrizes utilizadas; e estas, por serem nativas, não estão sujeitas a tratos culturais como adubação, podendo apresentar diferentes qualidades fisiológicas no momento da coleta. A mortalidade das estacas é variável de acordo com as condiçóes intrínsecas das mesmas e as condições ambientais (HARTMANN et al., 2011)

De acordo com os resultados de mortalidade e enraizamento, o substrato vermiculita: Plantmax ${ }^{\oplus}$ não é indicado para o desenvolvimento de mudas de Pereskia aculeata, visto que apresentou menores porcentagens de enraizamento em todas as estaçóes do ano e, consequentemente, maiores porcentagens de estacas mortas.

Para a variável estaca com novas brotaçóes, o uso dos substratos vermiculita:casca de arroz carbonizada e Plantmax ${ }^{\oplus}$, não apresentou diferença significativa em todas as estaçóes estudadas. $\mathrm{O}$ uso da vermiculita:Plant$\max ^{\oplus}$ apresentou maior porcentagem de estacas brotadas no outono $(75,00 \%)$ não diferindo estatisticamente apenas da estação de inverno (58,75\%) (Tabela 6).

Tabela 6 - Porcentagem de estacas brotadas em Pereskia aculeata Mill., coletadas nas quatro estaçôes do ano e submetidas a tratamentos com diferentes tipos de substrato, Curitiba (PR), 2015.

\begin{tabular}{ccccc}
\hline Trat & Out & Inv & Prim & Verăo \\
\hline V & $50,00 \mathrm{bB}$ & $85,00 \mathrm{aA}$ & $85,00 \mathrm{aA}$ & $78,75 \mathrm{aA}$ \\
V:C & $73,75 \mathrm{aA}$ & $85,00 \mathrm{aA}$ & $90,00 \mathrm{aA}$ & $81,25 \mathrm{aA}$ \\
V:P & $75,00 \mathrm{aA}$ & $58,75 \mathrm{bAB}$ & $26,25 \mathrm{bC}$ & $36,25 \mathrm{bBC}$ \\
$\mathrm{P}$ & $87,50 \mathrm{aA}$ & $82,50 \mathrm{aA}$ & $77,50 \mathrm{aA}$ & $86,25 \mathrm{aA}$ \\
\hline CV $(\%)$ & \multicolumn{4}{c}{17,21} \\
\hline
\end{tabular}

$\mathrm{V}=$ vermiculita; $\mathrm{V}: \mathrm{C}=$ vermiculita:casca de arroz carbonizada; $\mathrm{V}: \mathrm{P}=$ vermiculita:Plantmax $; \mathrm{P}=$ Plantmax $; \mathrm{CV}=$ coeficiente de variação. Médias seguidas de mesma letra na coluna (minúscula) e na linha (maiúscula) não diferem estatisticamente pelo teste de Tukey ao nível de 5\% de significância
As estaçóes de inverno, primavera e verão apresentaram menor porcentagem de estacas com novas brotaçóes quando do uso do substrato vermiculita:Plant$\max ^{\oplus}, 58,75 \%, 26,25 \%$ e $36,25 \%$ respectivamente. Já no outono, o uso da vermiculita proporcionou menor porcentagem de estacas brotadas $(50,00 \%)$ quando comparada com o uso dos demais substratos (Tabela 6).

Ao analisar a variável estacas que mantiveram as suas folhas iniciais, pode-se observar que os substratos vermiculita:Plantmax e Plantmax ${ }^{\oplus}$, não apresentaram diferença significativa em todas as estaçóes do ano (Tabela 7). O uso da vermiculita no inverno apresentou maior porcentagem de estacas que mantiveram as suas folhas iniciais $(98,75 \%)$, diferindo significativamente das demais estaçóes do ano. $\mathrm{O}$ uso da vermiculita:casca de arroz carbonizada no outono mostrou uma maior manutenção das folhas originais $(55,00 \%)$, diferindo apenas da estação de verão $(30,00 \%)$.

Tabela 7 - Porcentagem de estacas que mantiveram suas folhas iniciais em Pereskia aculeata Mill., coletadas nas quatro estaçóes do ano e submetidas a tratamentos com diferentes tipos de substrato, Curitiba (PR), 2015.

\begin{tabular}{ccccc}
\hline Trat & Out & Inv & Prim & Verão \\
\hline V & $0,00 \mathrm{dC}$ & $98,75 \mathrm{aA}$ & $62,50 \mathrm{bB}$ & $71,25 \mathrm{aB}$ \\
V:C & $55,00 \mathrm{bA}$ & $48,75 \mathrm{bAB}$ & $38,75 \mathrm{cAB}$ & $30,00 \mathrm{bB}$ \\
V:P & $22,50 \mathrm{cA}$ & $15,00 \mathrm{cA}$ & $3,75 \mathrm{dA}$ & $8,75 \mathrm{cA}$ \\
$\mathrm{P}$ & $86,25 \mathrm{aA}$ & $80,00 \mathrm{aA}$ & $95,00 \mathrm{aA}$ & $78,75 \mathrm{aA}$ \\
\hline CV (\%) & \multicolumn{4}{c}{20,98} \\
\hline
\end{tabular}

$\mathrm{V}=$ vermiculita; $\mathrm{V}: \mathrm{C}=$ vermiculita:casca de arroz carbonizada; $\mathrm{V}: \mathrm{P}=$ vermiculita:Plantmax $; \mathrm{P}=$ Plantmax $; \mathrm{CV}=$ coeficiente de variaçăo. Médias seguidas de mesma letra na coluna (minúscula) e na linha (maiúscula) não diferem estatisticamente pelo teste de Tukey ao nível de 5\% de significância

O substrato Plantmax ${ }^{\oplus}$ nas estações de outono e primavera foi o que apresentou maior porcentagem de estacas que mantiveram suas folhas iniciais, $86,25 \%$ e $95,00 \%$, respectivamente. Já nas estaçōes do inverno e verão, Plantmax não diferiu estatisticamente da vermiculita (Tabela 7).

$\mathrm{O}$ uso do substrato vermiculita:Plantmax ${ }^{\oplus}$ no inverno, primavera e veráo apresentou as menores porcentagens de estacas que mantiveram as folhas iniciais, com $15,00 \%, 3,75 \%$ e $8,75 \%$, respectivamente, sendo que nessas estaçóes apresentaram concomitamtemente as menores porcentagens de estacas enraizadas. Com isso, pode-se dizer que a presença das folhas durante todo o processo de enraizamento é de suma importância para o sucesso do mesmo, uma vez que as folhas são as responsáveis pela continuação do processo de fotossíntese, sintetizando carboidratos, além de serem fonte de auxinas e outros compostos, 
os quais translocados para a base das estacas, estimulam o enraizamento (HARTMANN et al., 2011).

\section{CONCLUSÃO}

Nas condições em que foi realizado o presente experimento, pode-se concluir que Pereskia aculeata é uma espécie de fácil enraizamento, sendo sua rizogênese direta. O material vegetal pode ser coletado nas quatro estaçóes do ano, recomendando-se o uso do substrato Plantmax ${ }^{\oplus}$ para obtenção de maior enraizamento e respectivas massa fresca e seca de raízes/estaca.

\section{REFERÊNCIAS}

CARDOSO, C. et al. AIB e substratos no enraizamento de estacas de pessegueiro 'Okinawa' coletadas no outono. Ciências Agrárias, v. 32, n. 4, p. 1307-1314, 2011.

CAVALCANTI, N. B; REZENDE, G. M. Efeito de diferentes substratos no desenvolvimento do Mandacaru sem espinhos (Cereus jamacaru P.DC.), Facheiro (Pilosocereus pachycladus Ritter), Xiquexique (Pilosocereus gounellei (A. Webwr Ex K, Schum) Bly. Ex Rowl) e Coroa-de-Frade (Melocactus babiensis Britton \& Rose). Revista Caatinga, v. 20, n. 1, 2007.

DUARTE, M. R.; HAYASHI S. S. Estudo anatômico de folha e caule de Pereskia aculeata Mill.(Cactaceae). Revista Brasileira de Farmacognosia, v. 15, n. 2, p. 103-109, 2005.

FACHINELLO, J. C.; HOFFMANN, A.; NACHTIGAL, J. C. Propagaçáo de plantas frutíferas de clima temperado. 2. ed. Pelotas: Universitária, 1995. 178 p.

FERRAZ, M. V.; CETURION, J. F; BEUTLER, A. N. Caracterizaçăo física e química de alguns substratos comerciais. Acta Scientia Agronomica, v. 27, n. 2, p. 209-214, 2005.

GONÇALVES, A.L. Substratos para produçấo de mudas de plantas ornamentais. In: MINAMI, K. Produçáo de mudas de alta qualidade em horticultura. São Paulo: T.A. Queiroz, 1995.

HARTMANN, H. T. et al. Plant propagation: principles e practices. 8th ed. Boston: Prentice Hall, 2011. 915 p.

HIGA, K. M.; FIOR, C. S.; RODRIGUES, L. R. Ensaios para a propagaçáo in vivo e in vitro de ora-pro-nobis (Pereskia aculeata). Pesquisa Agropecuária Gaúcha, v. 18, n. 1, p. 59-66, 2012.

LIMA, D.M. et al. Enraizamento de miniestacas de espinheira-santa (Maytenus ilicifolia Mart. Ex Reissek) em diferentes substratos. Ciência e Agrotecnológia, v. 33, n. 2, p. 617-623, 2009.
MANKE E. Cactus. 1 ed. [S.I.]: Barron, 1998.

OLIVEIRA, A. F. et al. Estaquia de oliveira em diferentes épocas, substratos e doses de AIB diluído em $\mathrm{NaOH}$ e álcool. Ciência e Agrotecnologia, v. 33, n. 1, p. 79-85, 2009.

PIO, R. et al. Substratos no enraizamento de estacas herbáceas de figueira oriundas de desbrota. Ciência e Agrotecnologia, v. 29, n. 3, p. 604-609, 2005.

REIS, J. M. R. et al. Efeito do estiolamento e do ácido indolbutírico no enraizamento de estacas do porta enxerto Pyrus calleryana Dcne. Ciência e Agrotecnologia, Lavras, v. 24, n. 4, p. 931-938, 2000.

ROSA, S. M.; SOUZA, L. A. Morfo-anatomia do fruto (hipanto, pericarpo e semente) em desenvolvimento de Pereskia aculeata Miller (Cactaceae). Biological Sciences, v. 25, n. 2, p. 415-428, 2003.

SARZI, I.; PIVETTA, K. F. L. Efeito das estaçóes do ano e do ácido indolbutírico no enraizamento de estacas de variedades de minirroseira (Rosa spp.). Revista Científica, v. 332, n. 1, p. 62-68, 2005.

SKREBSKY, E. C.; NICOLOSO, F. T.; MALDANER, J. Substratos na aclimatização de Pfaffia glomerata (Spreng) Pedersen produzida in vitro sob diferentes doses de sacarose. Ciência Rural, v. 36, n. 5, p. 1416-1423, 2006.

SOUSA, P. B. L.; AYALA-OSUNA, J. T.; GOMES, J. E. Propagaçáo vegetativa de Ocimum gratissimum $\mathrm{L}$. em diferentes substratos. Revista Brasileira de Plantas Medicinais, v. 8, n. 1, p. 39-44, 2005.

SOUZA, P. V. D.; CARNIEL, E.; FOCHESATO, M. L. Efeito da composição do substrato no enraizamento de estacas de maracujazeiro azedo. Revista Brasileira de Fruticultura, v. 28, n. 2, p. 276-279, 2006.

SOUZA, V. C.; LORENZI, H. Botânica Sistemática: guia ilustrado para identificaçáo das famílias de angiospermas da flora brasileira, baseado em APG II. Nova Oddessa, São Paulo: Instituto Plantarum, p. 230-231, 2005.

TAKEITI, C. Y. et al. Nutritive vegetable (Pereskia aculeata Mill). Internacional Journal of Food Sciences and Nutrition, v. 60, n. 1, p. 1-13, 2009.

TAVARES, I. B. et al. Tipos de estacas e diferentes substratos na propagação vegetativa da erva cidreira (Quimiotipos I, II e III). Bioscience Journal, v. 28, n. 2, p. 206-213, 2012.

VOZZO, J. A. Tropical tree seed manual. Washington: U.S. Department of Agriculture, 2002. 899 p. 